\title{
GESTA HERÓICA, OCULTAMIENTO HISTÓRICO E IDENTIDAD DE CLASE. LA PRENSA COSTARRICENSE Y EL $1^{\circ}$ DE MAYO (1858-1913)
}

\section{HEROIC FEAT, HISTORICAL HIDING AND IDENTITY OF CLASS. COSTA RICAN PRESS AND MAY 1ST. (1858-1913)}

\author{
Chester Urbina Gaitán*
}

RESUMEN

La celebración del $1^{\circ}$ de Mayo en Costa Rica, durante el período 1858-1913, pasó por diferentes momentos: primero, se vinculó a la restauración de la unión centroamericana; no obstante, fue olvidado por la prensa nacional. Posteriormente, se liga a la exaltación de la Campaña Nacional y a la deshonra nacional que se dio con el fusilamiento de Juan Rafael Mora y del General José María Cañas. A partir de 1913, los intelectuales ligados al Centro Germinal presentaron la celebración del $1^{\circ}$ de Mayo como día internacional de los trabajadores, dándole un carácter internacionalista y revolucionario.

PALABRAS CLAVE: COSTA RICA * HISTORIA * NACIONALISMO * PRENSA * INTELECTUALES

\section{ABSTRACT}

The celebration of May Day in Costa Rica during the period 1858-1913 went through different stages: first was linked to the restoration of the Central American Union, then was forgotten by the national press, then ligated to the exaltation of the National Campaign and national disgrace that came with the shooting of Juan Rafael Mora and General José María Cañas. From 1913 Intellectuals linked to the Germinal Center presented the celebration of May Day as International Workers Day giving an internationalist and revolutionary character.

KEYWORDS: COSTA RICA * HISTORY * NATIONALISM * PRESS * INTELLECTUALS

\footnotetext{
* Universidad Politécnica de Nicaragua (UPOLI).
} chesterurbina@yahoo.com 


\section{INTRODUCCIÓN}

El 1 de mayo de 1857, William Walker firma su capitulación de guerra contra las tropas centroamericanas en Rivas, ante el capitán estadounidense Charles Henry Davis (Obregón, 1976: 217). Con este hecho se da por concluida la llamada Campaña Nacional de 1856-1857, gesta heroica con la cual Costa Rica hizo respetar su soberanía y sirvió de base para la construcción de la memoria y la identidad nacional a finales del siglo xix (Molina y Palmer, 2004: 257-323; Molina, 2007: 111-129 y Díaz, 2007: 63-136). En octubre de 1857, el gobierno de Costa Rica decretó la construcción de un monumento a los héroes de la guerra en el Parque Central de San José $y$ además estableció el $1^{\circ}$ de mayo como día feriado, como recordatorio de la rendición del filibustero (Archivo Nacional de Costa Rica. Congreso 5189). Pese a todo lo anterior, lo que se ha resaltado sobre la celebración del 1 de mayo es que fue el Centro Germinal quien lo declaró como Día Internacional de los Trabajadores (De la Cruz, 1985 y Oliva, 1987). Empero, debe aclarase que el $1^{\circ}$ de mayo como Día internacional de los Trabajadores fue declarado de esa forma en un Congreso Obrero Socialista celebrado en París en 1889, que acordó reiniciar la lucha a partir del $1^{\circ}$ de mayo de 1890 .

Por ser una de las acciones más importantes en las que participó el Centro Germinal, la conmemoración del $1^{\circ}$ de mayo de 1913 guarda especial relevancia para entender la labor de dicho grupo. Esto se debe a varias razones como: constituir la primera conmemoración "oficial" por organizaciones sociales del país, tratarse de una de las fechas más importantes para el anarquismo internacional $y$ por ser uno de los momentos en que se puede leer con más firmeza el discurso anarcosindicalista en Costa Rica (Llaguno, 2010: 163). A un nivel general, los discursos de varios miembros de esta agrupación sobre el festejo de esta fecha en 1913, le dan una orientación clasista y revolucionaria. Al respecto, debe señalarse que el $1^{\circ}$ de mayo no fue una fecha del anarquismo internacional, los anarquistas participaron de esa lucha, pero no fue su lucha. Tampoco el discurso obrero en el país en ese período fue anarcosindicalista.

La celebración del $1^{\circ}$ de mayo como rendición de Walker se le debe a Joaquín García Monge en 1913 (Montanaro, 1981: 13). En el 2006, Acuña señala que hay que rescatar el $1^{\circ}$ de mayo como fecha en la que Walker se rinde a las fuerzas centroamericanas. Seis años después, Molina acota que el $1^{\circ}$ de mayo no se podía celebrar como una fecha gloriosa debido a que el jefe filibustero se rindió ante el capitán Davis y no ante los centroamericanos. José Joaquín Mora, jefe supremo de las fuerzas de Centroamérica y hermano del presidente Juan Rafael Mora, fue duramente criticado por los demás jefes militares por aceptar un acuerdo bajo estas condiciones. Sobre esto es necesario explicar que aunque la rendición de Walker no se haya hecho ante autoridad nacional, esto no le resta mérito al acontecimiento. La rendición se produce porque Walker tenía perdida la guerra y prefirió rendirse ante el capitán Davis, porque sabía que con él su vida no correría peligro, mientras que con Mora sería fusilado de inmediato. Lejos de ser una conmemoración simplemente asociada con "los mártires de Chicago", el $1^{\circ}$ de mayo, desde la década de 1910, empezó a ser celebrado en Costa Rica como una efeméride internacionalista de los trabajadores, en la que se denunciaban las formas locales de injusticia y explotación. Posteriormente, la celebración adquirió también un carácter antiimperialista, que se acentuó en el decenio de 1930, bajo el liderazgo del Partido Comunista (1931) (Molina, 2012).

Fundamentado en todo lo anterior, el presente artículo tiene como objetivo estudiar los discursos periodísticos emitidos sobre la celebración del $1^{\circ}$ de mayo durante los años de 1858 a 1913, es decir, desde su primer recordatorio como fecha de la capitulación de William Walker hasta su celebración como día internacional de los trabajadores. Para ello se revisaron periódicos como Crónica de Costa Rica, La Gaceta, Diario de Costa Rica, La República, La Prensa Libre, La Unión Católica, El Día, La Tribuna, Hoja Obrera y El Bombo. 
FECHA PATRIÓTICA, MARGINACIÓN POLÍTICA Y REFORMULACIÓN OBRERA: EL 1 DE MAYO EN COSTA RICA (1858-1913)

Para el $1^{\circ}$ de mayo de 1858 , el periódico Crónica de Costa Rica manifestaba el interés por la unión centroamericana:

Hoy celebramos el primer aniversario de la rendición de Rivas; de la restauración de Centro-América... Grande fue nuestro triunfo, más con él, solo hemos conseguido la probabilidad de un feliz porvenir... De Centro-América, creemos que se halla en la alternativa de ligarse por medio de una razonable confederación (sin perder más tiempo) o desaparecer del catalogo de los pueblos libres (1858:1-2).

Después de esta publicación pasaran 27 años sin que el $1^{\circ}$ de mayo sea recordado por la prensa, debido a la política antimorista de José Maria Montealegre y al nacionalismo personalista de Tomás Guardia (Taracena y Piel, 1995: 76).

El rescate del $1^{\circ}$ de mayo como fecha de la capitulación de William Walker se vuelve a dar hasta 1885, en un artículo de La Gaceta, en el cual se rescata la lección patriótica dada por los héroes de la Campaña Nacional:

Aún dado el caso desgraciadísimo de que el amor a lo frívolo llegase a enfriar en nuestros corazones el entusiasmo por lo generoso, todavía podríamos retemplar el espíritu con solo inclinarnos sobre los sepulcros que guardan las cenizas de los mil héroes que fueron amparo de nuestra libertad: nos regeneraríamos entonces sintiendo el inmortal aliento de los espíritus fuertes que ardieron en el fuego tres veces santo del más puro patriotismo (1885: 311).

La recuperación del $1^{\circ}$ de mayo en 1885 , está ligada al rescate de la figura de Juan Santamaría en medio de un contexto de oposición al proyecto unionista del gobernante guatemalteco Justo Rufino Barrios, así como de la invención y la transmisión de la identidad nacional costarricense.
Asimismo, el Diario de Costa Rica publicó en 1885, un fragmento del discurso del Mensaje del Presidente Juan Rafael Mora Porras al Congreso en 1856, donde se enfatiza las características esenciales de la identidad nacional de los costarricenses: "El espíritu laborioso de los costarricenses, su respeto al orden, su amor a la propiedad, y el acuerdo constante de la nación con el Gobierno...Ese ejército de labradores y artesanos, ese ejército de pacíficos y honrados propietarios..." (Diario de Costa Rica, 1885: 1).

Sobre estas particularidades, Acuña ha señalado que desde los primeros años de vida independiente en el país, ha existido un discurso que exalta que la población costarricense contaba con una serie de virtudes ejemplares como la tranquilidad, la neutralidad, el progreso, el pacifismo, un espíritu de negociación, un carácter industrioso y laborioso, $y$ un pueblo compuesto por propietarios (Acuña, 2002: 191-228).

Para 1889, se desatienden los rasgos identitarios del costarricense $y$ el discurso se centra en el ejército: "este acontecimiento que llena de gloria y justo orgullo a nuestro ejército, y que dio libertad a Centro América..." (La República, 1889: 2). Esta exaltación al cuerpo castrense radica en el hecho de que con la llegada al poder del General Tomás Guardia Gutiérrez en 1870, los militares asumen la dirección del Estado. Durante sus mandatos, se deshizo de la influencia de la oligarquía cafetalera en el poder político, con lo que obtuvo estabilidad. Para esto tuvo que despolitizar y reorganizar el ejército. Además, fomentó el desarrollo burocrático del Estado y la construcción de obras públicas, principalmente la del ferrocarril al Atlántico (Díaz, 2005: 44-45). Asimismo, hasta la segunda década del siglo xx, la clase dominante costarricense apoyó económicamente más al ejército que al sector educación (Palacios y Rojas, 1992). En 1890 , se consagra el $1^{\circ}$ de mayo como fecha de la segunda independencia del país:

El perdón magnánimo sello la épica grandeza de la lucha por la segunda independencia de la Patria, ya que la primera no costó ni sangre ni lagrimas...Los detalles de esa lucha gigantesca relativamente, están grabados en la memoria 
de todos los hijos de este suelo envidiable por feliz, uno por la raza que lo habita, inconquistable por su historia...La Patria festeja hoy la institución de sus libertades, el régimen gubernativo del pueblo, por el pueblo y para el pueblo... (La Prensa Libre, 1890: 283).

Según se observa en esta cita, se establece que el $1^{\circ}$ de mayo constituye la fecha fundacional de la vida política democrática en Costa Rica, lo que le da un carácter exaltivo. Sin embargo, debe precisarse que en el país después de los acontecimientos del 7 de noviembre de 1889, han surgido los partidos políticos y se ha establecido que el $1^{\circ}$ de mayo, el Presidente de la República rinda un informe anual de su gestión ante los diputados.

El 3 de mayo de 1893, La Unión Católica indicaba que en el día del Juicio Final, los mártires de la Campaña Nacional servirán de fiscales a Dios contra los que tienen ambición $y$ sed de mando, odio miserable, mezquinos intereses personales y se apropian de la riqueza pública (La Unión Católica, 1893: 572). Este discurso se da en medio de un contexto adverso a la Iglesia donde el Estado pretende limitar la influencia social de esta institución, tales como la suspensión del orden constitucional al impedir a la prensa católica publicar artículos en contra de las medidas liberales, la expulsión del Obispo Thiel y de la Compañía de Jesús, el impedimento a la instalación en el país de órdenes monásticas, secularización de los cementerios, derogación del Concordato y prohibición al clero de cualquier injerencia en la organización de la enseñanza pública (Vargas, 1991: 145).

Para 1894, se resalta que el $1^{\circ}$ de mayo de 1857 se selló la autonomía política de Centroamérica, se subraya el hecho que la Campaña Nacional fue una guerra de independencia, de sostenimiento de nuestra raza, lengua, instituciones $y$ costumbres. Se indica que en esta lucha sobresalen los jefes como Juan Rafael y José Joaquín Mora Porras, así como el héroe Juan Santamaría (La Prensa Libre, 1894: 2). En 1895, un periódico nacional acota que para los costarricenses tiene más significado el $1^{\circ}$ de mayo de 1857 que el 15 de setiembre de 1821, ya que si en la última fecha se proclamó la independencia, en la Campaña Nacional se defendió nuestra autonomía con un heroísmo inesperado (La Prensa Libre, 1895: 2). También para el $1^{\circ}$ de mayo de 1895, el abogado cubano Dr. Antonio Zambrana ofreció un discurso ante el Congreso Nacional, en el cual resalta la gesta de la Campaña Nacional, las batallas de Santa Rosa y Rivas, y el heroísmo de Juan Santamaría. Exalta a José Joaquín Mora y oculta lo sucedido sobre la permisión de este en la capitulación de William Walker ante un oficial estadounidense $y$ no ante los jefes militares centroamericanos al señalar:

...que vuestro José Joaquín Mora, si no famoso por grandes talentos militares, que no había tenido oportunidad de cultivar, lucio condiciones distinguidísimas de inteligencia y de carácter, capaces de llevarlo con prestigio, y con prestigio conservarlo desde su nombramiento hasta los últimos días de la guerra, al frente de todo el ejército centroamericano... (Zambrana, 1895: 13).

Es evidente el interés de ocultar lo sucedido en la capitulación de Walker, ya que el interés de Zambrana es el de exaltación de la Nación y no contar lo que narra el hecho histórico (White, 2003 y Carr, 1993).

Para 1897, se señala que a pesar de que las pretensiones de William Walker fueron frenadas el $1^{\circ}$ de mayo de 1857 , en la región centroamericana subsisten los golpes de estados $y$ las dictaduras (La Prensa Libre, 1897: 2). Lo expuesto sobre el $1^{\circ}$ de mayo, demuestra lo señalado por Patricia Vega en el sentido de que los periódicos son elementos fundamentales en la creación, el desarrollo y la consolidación de la nacionalidad costarricense en las décadas de 1880 y 1890 (1996: 160). Para 1902, en El Día se rescata el fusilamiento del presidente Juan Rafael Mora y del General José María Cañas, así como, el hecho de que los costarricenses no han sabido hacer feliz al país y que probablemente no sabrán hacerlo libre (El Día, 1902). En 1909, el periódico La Tribuna resaltaba: "A partir de ella en aquel entonces de los lejanos períodos de la campaña nacional, se borraron 
en el horizonte político esas nubes de peligros hondos que pusieron en amenaza la dignidad de la República y el decoro de la Patria CentroAmericana" (La Tribuna, 1909: sp).

En 1913, el periódico la Hoja Obrera sacaba a la luz un artículo de José María Zeledón titulado "Primero de mayo" donde acota: "Es una hermosa fiesta del internacionalismo obrero que simboliza la vida solidaria de los trabajadores del mundo" (Hoja Obrera, 1913: sp). Zeledón es un intelectual que destacó por oponerse al patriotismo al considerarlo:

...una deidad sangrienta y cruel que se alimenta con sangre de los pueblos $y$ gusta de las innobles hecatombes que llamamos batallas, en las cuales pierde sus más hermosas flores el árbol de la juventud. El patriotismo es la concepción más siniestra del egoísmo humana, que ha sembrado el mundo de fronteras $y$ enciende la guerra entre los pueblos (2003, citado en Oliva, 2011: 82).

El comité organizador de la celebración del $1^{\circ}$ de mayo de 1913 redactó un manifiesto en donde se acuerda invitar a todos los trabajadores a conmemorar el $1^{\circ}$ de mayo, excitarlos a que suspendan sus tareas, dar a conocer que la fecha significa la lucha por la emancipación proletaria $y$ fomentar un plan de lucha emancipadora para los obreros de Costa Rica ( $E l$ Bombo, 1913).

Los discursos contestatarios de Zeledón $y$ del comité organizador se contraponen con el de promoción de la identidad nacional promovido por la prensa liberal y católica, ya que desde finales de los años 80 del siglo xix, en Costa Rica se da un proceso de expansión de las organizaciones de trabajadores por medio de la creación de sociedades mutualistas, cooperativas, sociedades de artesanos y clubes políticos. Entre 1880 y 1930, el movimiento obrero se preocupó por la preparación intelectual de los trabajadores, impulsó la creación de escuelas nocturnas, de centros de tertulia y bibliotecas. En 1889, se establecieron las primeras bibliotecas populares formadas por los trabajadores, como la de la Sociedad de Artesanos de San José y la de la Sociedad de Artes y Oficios. Estas bibliotecas albergaban revistas $y$ periódicos nacionales $y$ extranjeros, así como, una selecta colección de libros (Oliva, 1985; Molina, 1995: 129-149; Acuña, 1993: 255-323 y 1986; Acuña y Molina, 1986 y 1991).

\section{CONCLUSIÓN}

En 1858, el recuerdo de la capitulación de William Walker es vinculado a la restauración de la unión centroamericana. Entre 1859 y 1884, la prensa nacional no abordo este acontecimiento histórico debido a la política antimorista de José María Montealegre y al nacionalismo personalista de Tomás Guardia. A partir de 1885, su rescate se liga a la exaltación de la Campaña Nacional como hecho fundacional de la construcción de la memoria y la identidad nacional. Empero, en los discursos periodísticos, el $1^{\circ}$ de mayo estuvo ligado a la exaltación del ejército, su papel como fecha fundacional de la vida política democrática en Costa Rica, la impugnación de las leyes liberales de 1884, la exaltación de José Joaquín Mora y la ignominia que se dio con el fusilamiento de Juan Rafael Mora y del General José María Cañas. Los intelectuales que escribían en la prensa obrera - ligados al Centro Germinal- se apropiaron y replantearon en 1913, la celebración del $1^{\circ}$ de mayo como Día Internacional de los Trabajadores, dándole un carácter internacionalista y revolucionario, convirtiéndolo en un elemento de su identidad de clase. A partir de este año, la celebración adquirió un carácter popular y dejo de convertirse en una apología a la Campaña Nacional y a Juan Rafael Mora Porras.

\section{BIBLIOGRAFÍA}

\section{LIBROS}

Acuña Ortega, Víctor Hugo. Los orígenes de la clase obrera en Costa Rica: las huelgas de 1920 por la jornada de ocho horas. San José, Costa Rica: Centro Nacional de Acción Pastoral (CENAP) y Centro de Estudios para la Acción Social (CEPAS), 1986. 
Acuña Ortega, Víctor Hugo y Molina Jiménez, Iván. El desarrollo económico y social de Costa Rica: de la colonia a la crisis de 1930. San José, Costa Rica: Editorial Alma Máter, 1986.

Acuña Ortega, Víctor Hugo y Molina Jiménez, Iván. Historia económica y social de Costa Rica (1750-1950). San José, Costa Rica: Editorial Porvenir, 1991.

Acuña Ortega, Víctor Hugo (coordinador). Historia general de Centroamérica. Tomo IV: Las repúblicas agroexportadoras. Madrid, España: Ediciones Siruela, SA, 1993.

Carr, Edward H. ¿Qué es la historia? Barcelona, España. Editorial Planeta DeAgostini, 1993.

De la Cruz, Vladimir. Los mártires de Chicago y el 1 de mayo de 1913. San José, Costa Rica: Editorial Costa Rica (ECR), 1985.

Díaz Arias, David. Construcción de un estado moderno: política, estado e identidad nacional en Costa Rica, 1821-1914. San José, Costa Rica: Editorial de la Universidad de Costa Rica (EUCR), 2005.

Díaz Arias, David. La fiesta de la independencia en Costa Rica, 1821-1921. San José, Costa Rica: Editorial de la Universidad de Costa Rica (EUCR), 2007.

Molina, Iván y Palmer, Steven (editores). Héroes al gusto y libros de moda. Sociedad y cambio cultural en Costa Rica (17501900). San José: Editorial de la Universidad Estatal a Distancia (EUNED), 2004.

Molina Jiménez, Iván. El que quiera divertirse. Libros y sociedad en Costa Rica (1750-1914). San José: Editorial de la Universidad de Costa Rica, 1995.

Molina, Iván (editor). Industriosa y sobria. Costa Rica en los días de la Campaña Nacional (1856-1857). Vermont, Estados Unidos de América: Plumsock Mesoamerican Studies, 2007.

Montanaro Meza, Oscar. Cinco lecciones de Joaquín García Monge. San José, Costa Rica: Editorial de la Universidad de Costa Rica (EUCR), Centro Universitario de Occidente, 1981.
Obregón Loría, Rafael. Costa Rica y la guerra del 56. La campaña del tránsito 18561857. 2da edición. San José, Costa Rica: Editorial Costa Rica (ECR), 1976.

Oliva Medina, Mario. Artesanos y obreros costarricenses 1880-1914. San José, Costa Rica: Editorial Costa Rica (ECR), 1985.

Oliva Medina, Mario. $1^{\circ}$ de mayo en Costa Rica. 1913-1986. San José, Costa Rica: COMARFIL, 1987.

Taracena A., Arturo y Piel, Jean. Identidades nacionales y estado moderno en Centroamérica. San José: Editorial de la Universidad de Costa Rica (EUCR), 1995.

Vargas Arias, C. A. El liberalismo, la iglesia y el Estado en Costa Rica. San José, Costa Rica: Editorial Guayacán, 1991.

White, Hayden. El texto histórico como artefacto literario. Barcelona, España: Ediciones Paidós Ibérica SA, 2003.

\section{PUBLICACIONES PERIÓDICAS}

Acuña Ortega, Víctor Hugo. "La invención de la diferencia costarricense, 1810 1870". Revista de Historia 45. Heredia, Costa Rica. Editorial de la Universidad Nacional. Enero-junio, 2002: 191-228.

Crónica de Costa Rica. 1 Mayo de 1858. Año 2. No.110.

Diario de Costa Rica. Viernes 1 de mayo de 1885. Año I. No.96.

El Bombo. 19 de abril de 1913.

El Día. Jueves 1 de mayo de 1902. Año II. No.475.

Hoja Obrera 147. 6 de mayo de 1913.

La Gaceta. Viernes 1 de mayo de 1885. Año 8. No. 76.

La Prensa Libre. Jueves 1 de mayo de 1890. Año I. No.283.

La Prensa Libre. Martes 1 de mayo de 1894. Año V. No.1527.

La Prensa Libre. Miércoles 1 de mayo de 1895. Año VI. No.1826.

La Prensa Libre. Sábado 1 de mayo de 1897. Año VIII. No.2426.

La República. Miércoles 1 de mayo de 1889. Año III. No. 817.

La Tribuna 33. Sábado 1 de mayo de 1909. 
La Unión Católica. Miércoles 3 de mayo de 1893. Año IV. No.290.

Molina Jiménez, Iván. "Primero de mayo y clases trabajadoras". Periódico La Nación. 8 de mayo de 2012. En: <http:// www.nacion.com/2012-05-08/Opinion/ primero-de-mayo-y-clases-trabajadoras. aspx> [consultado el 3 de enero de 2013].

Oliva Medina, Mario. "La Revista Renovación 1911-1914: de la política a la literatura”. Revistas culturales e historia intelectual 50. Enero-junio-Julio-diciembre, 2011. En: <www.revistas.una.ac.cr/index. php/tdna/article/download/5524/5349> [consultado el 1 de marzo de 2013].

Vega Jiménez, Patricia. "De periodista a literato. Los escritores de periódicos costarricenses (1870-1890)". Anuario de Estudios Centroamericanos I (22). San José, Costa Rica. Editorial de la Universidad de Costa Rica-EucR. 1996: 149-163

\section{TEXTOS ELECTRÓNIOS}

Acuña, Víctor Hugo. Hay que rescatar el 1 de mayo del 57. En: <https://groups.google. com/forum/?hl=es\&fromgroups\#!topic/ boletinhistoria_ucr/MrGpbVJgBo0\%5B1$25 \% 5 \mathrm{D}>$ [consultado el 6 de mayo de 2013].

Díaz Arias, David. Héroes, dioses y credos: el centenario del héroe costarricense Juan Santamaría (1931). México DF, México. Asociación para el Fomento de los
Estudios Históricos en Centroamérica. Setiembre de 2010. En: <http://www. afehc-historia-centroamericana.org/ index.php?action $=$ fi_aff\&id $=2492>$ [consultado el 7 de febrero de 2013].

TESIS

Llaguno Thomas, José Julián. "Pensamiento anarquista, Cultura Política y Nueva Intelectualidad en Costa Rica (19001914)". [Tesis de Licenciatura en Ciencias Políticas]. San José, Costa Rica. Universidad de Costa Rica (UCR), 2010.

Palacios Robles, María de los Ángeles y Rojas Vargas, Andrea. "Génesis, evolución y papel ideológico de la educación cívica costarricense, 1821-1940". [Tesis de Licenciatura en Historia]. San José, Costa Rica. Universidad de Costa Rica (UCR), 1992.

OTROS

Archivo Nacional de Costa Rica. Congreso 5189. Reconocimiento a los Mora y Cañas por la guerra contra los filibusteros, 1857.

Zambrana, Antonio. Discurso pronunciado en la noche del 1 de mayo en el Salón del Congreso Nacional. San José: Tipografía de V. Lines, 1895.

Fecha de ingreso: 17/08/2012 Fecha de aprobación: 24/02/2014 
